\title{
Sistem Monitoring pada Tanaman Hidroponik menggunakan Arduino UNO dan NodeMCU
}

\author{
Syafei Karim \\ Teknologi Rekayasa Perangkat \\ Lunak, Politeknik Pertanian Negeri \\ Samarinda, \\ Samarinda, Indonesia \\ syfei.karim@gmail.com
}

\author{
Ida Maratul Khamidah \\ Teknologi Rekayasa Perangkat \\ Lunak, Politeknik Pertanian Negeri \\ Samarinda, \\ Samarinda, Indonesia \\ idamaratul@gmail.com
}

\author{
Yulianto \\ Teknologi Rekayasa Perangkat \\ Lunak, Politeknik Pertanian Negeri \\ Samarinda, \\ Samarinda, Indonesia \\ yulianto.title@yahoo.com
}

\begin{abstract}
Hidroponik merupakan cara bercocok tanam tanpa menggunakan tanah sebagai media tanamnya, tetapi menggunakan air yang mengandung nutrisi yang dibutuhkan oleh tanaman. Kelebihan teknik menanam hidroponik antara lain penggunaan lahan yang efisien, penggunaan pupuk dan air lebih efisien dan terkendali. Sedangkan kekurangan dari teknik ini adalah membutuhkan ketelitian, ketelatenan, dan pemantauan secara terus-menerus. Untuk mengatasi masalah tersebut maka dapat memanfaatkan kemajuan teknologi yang sudah berkembang. Saat ini banyak sistem yang mampu mengolah dan mengerjakan pekerjaan manusia yang dilakukan secara manual dapat menjadi lebih mudah, cepat, dan akurat baik dari segi waktu dan tenaga. Salah satunya adalah mikrokontroller Arduino Uno. Terdapat tiga sensor yang digunakan yaitu sensor DHT-22 untuk mendeteksi suhu dan kelembaban, sensor $\mathrm{pH}$ untuk mendeteksi nilai $\mathrm{pH}$, sensor TDS untuk mendeteksi nutrisi air pada tanaman. Data-data sensor tersebut dikendalikan oleh Arduino Uno dan datanya dikirim ke server Thingsboard menggunakan protokol MQTT yang datanya ditampilkan dalam bentuk chart dan grafik. Dari hasil pengujian modul sensor yang dilakukan, sensor sudah bekerja dengan baik dengan berdasarkan waktu dengan selisih satu jam.
\end{abstract}

Keywords-Internet of Things, Arduino Uno, Hidroponik, Sistem Monitoring

\section{INTRODUCTION}

Di Indonesia yang memiliki iklim tropis sangat bagus untuk menanam jenis sayuran sehingga banyak cara untuk budidaya tanaman sayuran yang semakin hari semakin berkembang. Saat ini, budidaya tanaman dengan cara organik sangat banyak diterapkan oleh para petani untuk mendapatkan hasil tanaman sayur yang baik dan berkualitas karena tidak menggunakan tambahan pupuk kimia, pestisida, herbisida, dan obat-obatan tanaman lainnya. Dalam hal bercocok tanam terdapat berbagai macam teknik, salah satu teknik yang bagus dan dapat menghemat lahan yaitu teknik menanam secara hidroponik.

Hidroponik merupakan cara bercocok tanam tanpa menggunakan tanah sebagai media tanamnya, tetapi menggunakan air yang mengandung nutrisi yang dibutuhkan oleh tanaman (Buana, et al., 2019). Beberapa pakar dibidang hidroponik mengatakan beberapa kelebihan dan kekurangan menggunakan teknik menanam hidroponik dibandingkan dengan teknik pertanian yang secara konvensional (Del Rosario, et al., 1990). Kelebihan teknik menanam hidroponik antara lain penggunaan lahan yang efisien, tanaman dapat berproduksi tanpa menggunakan tanah, kualitas produksi tanaman dapat lebih tinggi dan lebih bersih, dan penggunaan pupuk dan air lebih efisien dan terkendali. Sedangkan kekurangan dari teknik ini adalah membutuhkan ketelitian, ketelatenan, dan pemantauan secara terus-menerus (Prayitno, et al., 2017). Perubahan $\mathrm{pH}$ sangat mempengaruhi pertumbuhan, khususnya tanaman sayur. Hal lain yang perlu diperhatikan dalam menanam secara hidroponik yaitu penyiraman tanaman yang teratur agar tanaman dapat tumbuh dengan baik. Tetapi perawatan tanaman sesuai jadwal menjadi masalah bila tidak mempunyai banyak waktu untuk merawatnya. Pada sistem hidroponik, air dan nutrisi diberikan secara terkontrol dan dalam jumlah yang tepat. Hal ini dilakukan dengan cara mensirkulasikan nutrisi yang terlarut dalam air. Pada tanaman, $80-90 \%$ bagian tanaman tersebut terdiri atas air. Sehingga ketersediaan air yang berkualitas sangat penting untuk pertumbuhan tanaman. Kualitas air yang buruk dapat menyebabkan masalah toksisitas, penyakit, masalah pH, dan lain-lain (Putra, 2018).

Untuk mengatasi masalah tersebut agar tidak terjadinya penurunan kualitas tanaman maka dapat memanfaatkan kemajuan teknologi yang sudah berkembang. Saat ini banyak sistem yang mampu mengolah dan mengerjakan pekerjaan manusia yang dilakukan secara manual dapat menjadi lebih mudah, cepat, dan akurat baik dari segi waktu dan tenaga. Salah satunya adalah mikrokontroller Arduino Uno.

Arduino uno adalah sebuah board yang menggunakan mikrokontroller ATmega328. Alat ini dapat diprogram untuk melakukan perintah khusus yang sudah ditentukan. Pada kasus ini, alat akan diprogram untuk mendeteksi kadar $\mathrm{pH}$ air dan mendeteksi kondisi air pada tanaman hidroponik sehingga dengan alat ini dapat membantu petani dalam melakukan pemantauan pada tanamannya. 


\section{LITERATURE REVIEW}

\section{A. Scientific Study}

Berikut ini dipaparkan beberapa penelitian terkait seputar IoT pada tanaman hidroponik:

a) Penelitian yang dilakukan oleh (Ciptadi \& Hardyanto, 2018) adalah membuat sistem dengan menggunakan dua sensor yang terhubung dengan mikrokontroller Arduino Uno. Dua sensor tersebut adalah DHT11 untuk mengetahui temperature dan kelembapan. Sensor berikutnya adalah YF-S201 untuk mengukur intensitas nutrisi yang mengalir melalui gully. Dengan penerapan teknologi IoT ini dapat meminimalisasi intervensi manual dan menghasilkan system hidroponik yang cerdas.

b) Penelitian dilakukan oleh (Crisnapati, et al., 2018) yaitu menerapkan teknologi IoT yang digunakan pada tanaman hidroponik dengan teknologi NFT (Nutrient Film Technique). Sistem digunakan untuk monitor dan mengumpulkan informasi dari tanaman kemudian data tersebut di evaluasi dan analisis. Data dikirim menggunakan module Wi-Fi ESP8266 dan Raspberry Pi 2 Model B sebagai webserver untuk menyimpan data yang dikirimkan.

c) Penelitian dari (Arief, et al., 2020) dengan membuat smartgreenhouse untuk tanaman hidroponik. Sistem yang dibangun merupakan sistem pintar untuk pengaturan jumlah nutrisi secara automasi juga mengatur $\mathrm{pH}$ yang tepat untuk tanaman dengan media tanam hidroponik dengan dilakukan secara jarak jauh, kontinyu, dan real time, juga data historical.

d) Penelitian yang dilakukan (Prasetyo, et al., 2018) adalah membuat tanaman hidroponik menggunakan jenis hidroponik Deep Flow Technique (DFT) yang menerapkan aliran nutrisi secara kontinyu dan terdapat genangan setangah dari diameter pipa yang menggenangi akar tanaman. Penerapan IoT digunakan untuk mengantisipasi terjadinya perubahan pada unsur tumbuh tanaman. Data unsur tumbuh tanaman diakusisi oleh sensor yang terintegrasi dengan Raspberry Pi. Pada proses monitoring menggunakan website akan menampikan data unsur tumbuh tanaman berupa $\mathrm{pH}$, suhu, kelembaban dan ketinggian air pada tandon hidroponik. Suhu dan kelembaban digunakan sebagai parameter pengendali sirkulasi air yang diproses menggunakan Metode Fuzzy Sugeno untuk menyalakan atau mematikan pompa pada hidroponik DFT.

\section{B. Hidroponik NFT}

Hidroponik adalah cara bercocok tanam tanpa menggunakan media tanah, budidaya tanaman ini lebih

mengutamakan media air yang telah dicampur dengan nutrisi (Pamungkas, et al., 2017). Ada dua metode dan teknik yang dapat digunakan dalam hidroponik antara lain Deep Flow Technique, sistem Drip, Water culture, dan juga Nutrient Film Technique.
NFT Sistem merupakan tehnik hidroponik yang mempunyai aliran air dangkal mengandung nutrisi yang dibutuhkan untuk pertumbuhan tanaman, larutan nutrisi mengalir melalui saluran kedap air seperti pipa paralon, dengan kedalam sirkulasi aliran larutan nutrisi yang dangkal (Setiawan, 2018). Sistem NFT dirancang menggunakan saluran air dengan kemiringan yang tepat, panjang saluran air yang tepat serta laju aliran air yang tepat. Keuntungan dari sistem NFT adalah akar tanaman akan terkena cukup pasokan nutrisi, oksigen dan pasokan air. Sedangkan kerugiannya adalah tidak ada air yang mengalir jika terjadinya mati listrik. Pada gambar 1 meunjukkan sistem hidroponik dengan teknik NFT.

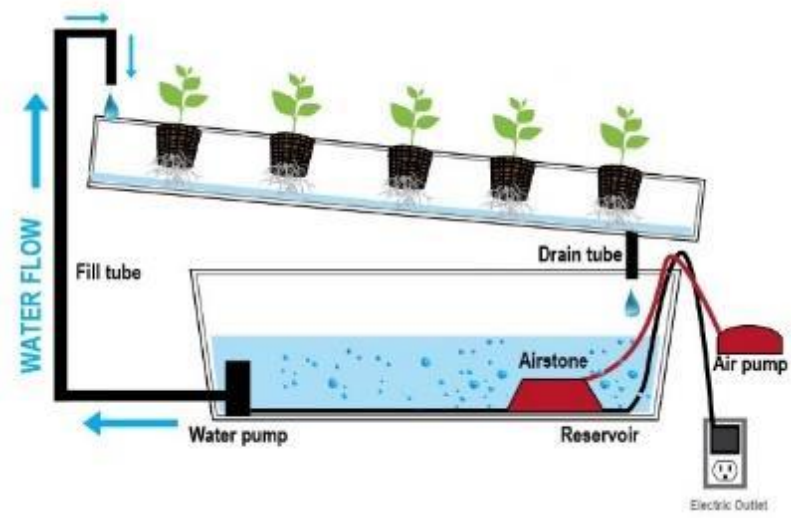

Gambar 1. Sistem Hidroponik NFT (Setiawan, 2018)

\section{Internet of Things (IoT)}

IoT adalah sebuah infrastruktur jaringan global, yang dapat mengubungkan perangkat keras dan virtual melalui eksploitasi data capture serta kemampuan komunikasi. Dalam infrastruktur terdiri dari jaringan yang sudah ada dan internet beserta pengembangan jaringannya. Sehingga, IoT ini menawarkan objek, sensor dan kemampuan koneksi agar dapat menyediakan layanan dan aplikasi ko-operatif yang independen. Menurut (Association, 2014), Internet of things (IoT) didefinisikan sebagai sebuah jaringan dengan masing-masing benda yang ternanam dengan sensor yang terhubung kedalam jaringan internet.

Konsep Internet of Things mencangkup tiga elemen utama yaitu: benda fisik atau nyata yang telah diintegrasikan pada modul sensor, koneksi internet, dan pusat data pada server untuk menyimpan data ataupun informasi dari aplikasi (Setiadi \& Muhaemin, 2018). Penggunaan benda yang terkoneksi ke internet akan menghimpun data yang kemudian terkumpul menjadi „big data ${ }^{\text {ee }}$ untuk kemudian diolah, dianalisa baik oleh instansi pemerintah, perusahaan terkait, maupun instansi lain kemudian di manfaatkan bagi kepentingan masingmasing. Pada gambar 2 menunjukkan konsep dari IoT.

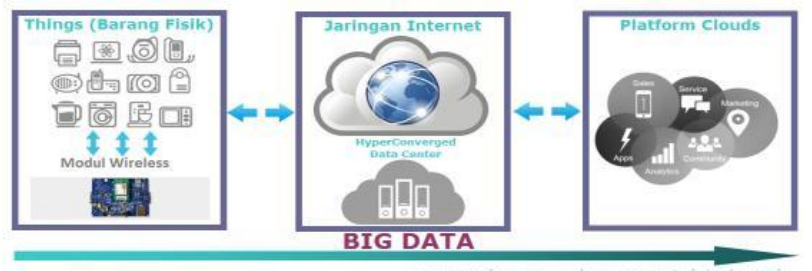

Gambar 2. Konsep IoT (Setiadi \& Muhaemin, 2018) 
Konsep IoT bisa diterapkan pada banyak hal contohnya monitoring lingkungan, pengelolaan infrastruktur, sensor peralatan, bidang kesehatan bahkan pada pertanian baik pertanian konvensional (media tanah) maupun pertanian hidroponik. Beberapa penerapan IoT bisa dilihat pada gambar 3 .
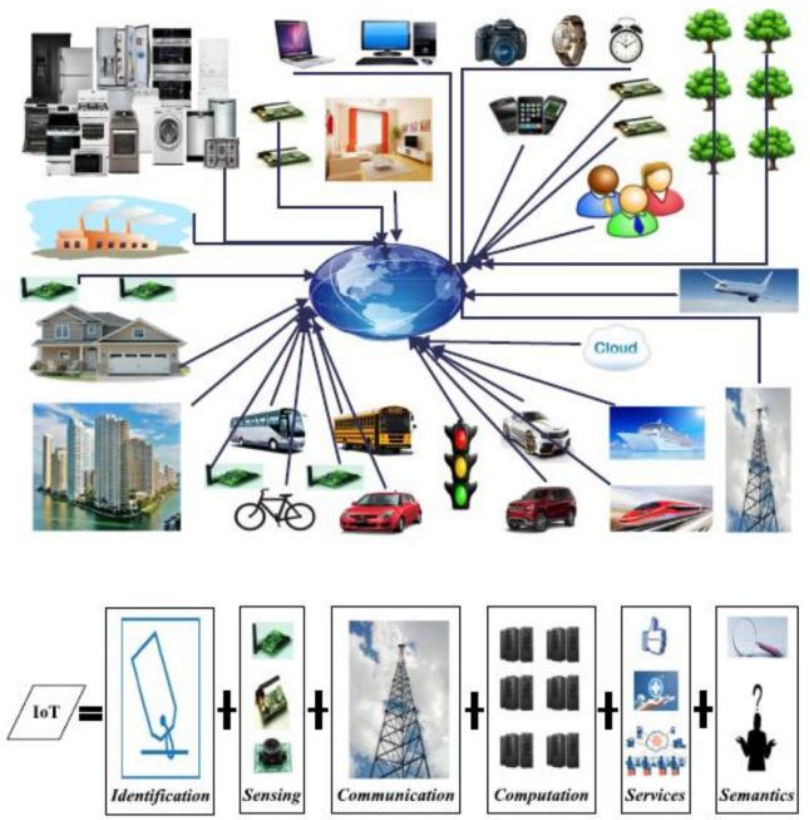

Gambar 3. Penerapan Internet of Things (Wilianto \& Kurniawan, 2018)

\section{REASEARH METHODS}

Metodologi yang akan digunakan dalam penelitian ini adalah dengan menggunakan metode Waterfall yang merupakan bagian dari model Software Development Life Cycle (SDLC). Tahapan dari model ini dimulai dari tahapan analisis sistem, desain sistem dan seterusnya hingga tahapan pemeliharaan sistem. Siklus dari model waterfall dapat dilihat pada gambar 4 .

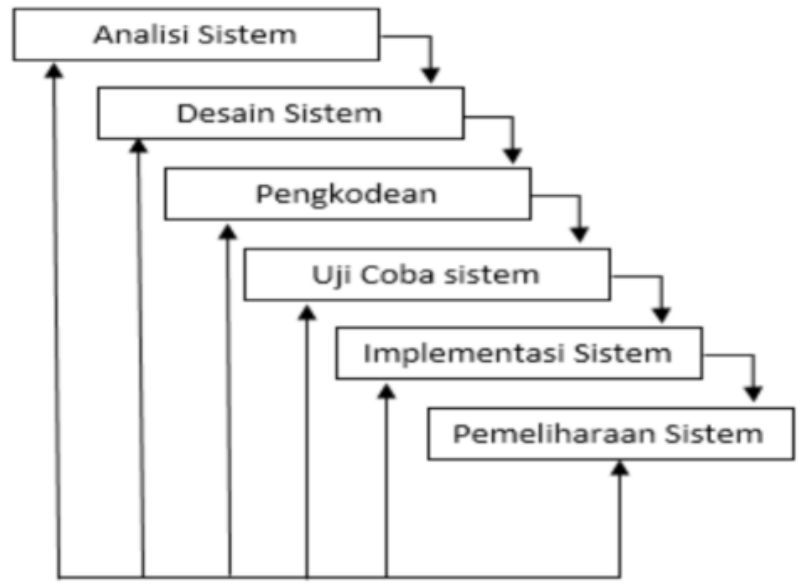

Gambar 4. Skema model Waterfall

\section{A. Analisis Sistem}

Pada tahapan analisis sistem, penulis menganalisis permasalahan yang terjadi dengan cara melakukan observasi pada tanaman hidroponik. Hal ini dilakukan untuk menentukan sensor-sensor yang akan digunakan.

\section{B. Desain Sistem}

Pada tahapan ini dilakukan untuk merancang sistem sesuai kebutuhan sistem yang akan dibangun berdasarkan hasil analisis yang sudah dilakukan. Penulis membuat rancangan sistem dan membuat skema cara kerja sistem kedalam bentuk diagram guna memberikan gambaran mengenai alur sistem yang dibuat, serta membuat skematik rangkaian alat yang akan digunakan untuk membangun sistem monitoring ini dengan menggunakan aplikasi Fritzing. Untuk lebih jelasnya bisa dilihat pada gambar 5.

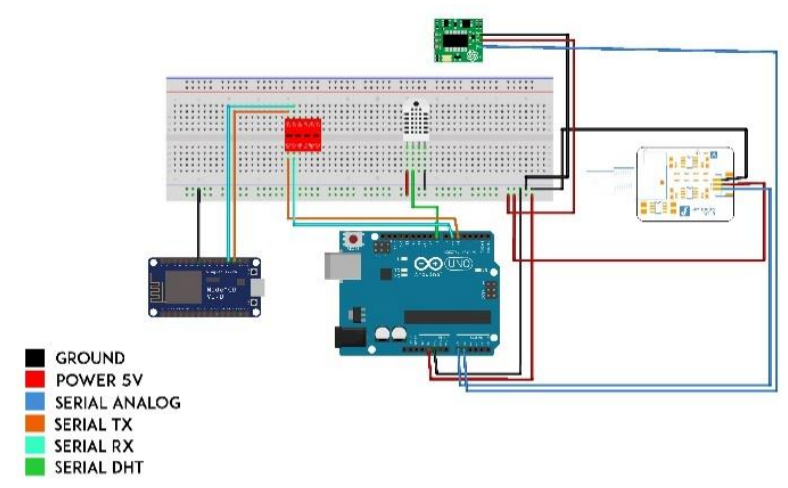

Gambar 5. Rancangan Sistem Smart Farming

\section{Pengkodean Program}

Tahapan pengkodean merupakan tahapan untuk menterjemahkan hasil dari desain sistem yang telah dibuat kedalam sebuah bahasa program yang dapat di proses oleh sebuah komputer. Pada tahapan ini penulis membuat kode program untuk memprogram mikrokontroller Arduino Uno sebagai pengontrol dari sensor-sensor yang akan digunakan dalam sistem smart farming dan board NodeMCU untuk pengiriman data ke server. Penulis menggunakan software arduino IDE untuk memprogram Arduino Uno dan NodeMCU agar dapat mentransmisikan data hasil dari hasil inputan oleh sensor-sensor yang digunakan.

\section{Uji Coba Sistem}

Pada tahapan uji coba sistem, penulis melakukan uji sistem pada perangkat sensor untuk mengetahui kinerja sensor bekerja dengan baik.

\section{E. Implementasi Sistem}

Tahapan ini merupakan tahapan untuk menerapkan sistem yang telah siap untuk digunakan dan telah melewati masa uji sistem, langkah-langkah dalam implementasi sistem sebagai berikut:

1. Menyiapkan perangkat

Mempersiapkan perangkat sistem Smart Farming yang telah dirancang dan dibangun dengan mengintegrasikan beberapa sensor.

2. Melakukan simulasi

Sistem Smart Farming dirancang dan dibangun dalam bentuk maket/prototipe sehingga perlu dilakukan simulasi untuk melihat cara kerja dari sistem Smart 
Farming. Sistem ini disimulasikan pada tanaman strawberry yang menggunakan alat humidifier.

\section{F. Pemeliharaan Sistem}

Pemeliharan sistem dilakukan agar sistem dapat terus bekerja dengan baik, terutama pada sensor-sensor yang digunakan perlu dilakukan kalibrasi secara rutin agar mendapatkan hasil pengukuran serta inputan untuk memonitoring secara presisi serta melakukan pengontrolan terhadap mikrokontroller untuk memastikan perangkat terus bekerja dengan baik dan benar.

\section{RESULTS AND DISCUSSIONS}

\section{A. Pengujian Pembacaan Modul Sensor}

Tujuan pengujian yang akan dilakukan adalah untuk mengukur dan mengetahui bagaimana pembacaan sensor DHT-22, sensor $\mathrm{pH}$, dan sensor TDS sebagai input data dari sistem monitoring pada tanaman hidroponik.

Tabel 1. Hasil Pengujian Modul Sensor

\begin{tabular}{|c|l|c|c|c|c|}
\hline No. & Waktu & $\begin{array}{c}\text { Suhu } \\
\left({ }^{\circ} \mathbf{C}\right)\end{array}$ & $\begin{array}{c}\text { Kelembaban } \\
(\mathbf{\%})\end{array}$ & $\mathbf{p H}$ & $\begin{array}{c}\text { TDS } \\
(\mathbf{p p m})\end{array}$ \\
\hline 1 & 08.00 & 27 & 99 & 6.4 & 1184 \\
\hline 2 & 09.00 & 27.3 & 99 & 6.38 & 1184 \\
\hline 3 & 10.00 & 27.5 & 99 & 6.34 & 1184 \\
\hline 4 & 11.00 & 27.9 & 99 & 6.37 & 1184 \\
\hline 5 & 12.00 & 28 & 99 & 6.34 & 1184 \\
\hline 6 & 13.00 & 28.3 & 97 & 6.33 & 1183 \\
\hline 7 & 14.00 & 28.4 & 95 & 6.30 & 1183 \\
\hline 8 & 15.00 & 28.1 & 93 & 6.27 & 1180 \\
\hline 9 & 16.00 & 27.8 & 96 & 6.15 & 1175 \\
\hline 10 & 17.00 & 27.5 & 98 & 6.09 & 1169 \\
\hline
\end{tabular}

Berdasarkan hasil pengujian modul sensor pada tabel 1 menunjukkan sensor berjalan dengan baik. Pada suhu dan kelembaban memiliki perbedaan nilai yang terlalu jauh. Hal ini dikarenakan sistem smart farming yang berdekatan dengan alat humidifier. Alat humidifier ini berfungsi untuk menurunkan suhu dan menaikkan kelembaban. Hal ini terlihat nilai kelembaban yang mencapai $99 \%$. Nilai menjadi turun dikarenakan suhu di siang hari yang meningkat sehingga memberi pengaruh pada turun naik nya nilai suhu dan kelembaban. Sedangkan nilai $\mathrm{pH}$ dan TDS semakin lama semakin menurun. Hal ini dikarenakan, nilai $\mathrm{pH}$ dan nutrisi air yang diserap oleh tanaman.

\section{B. Pengujian Konektivitas}

Tujuan pengujian ini adalah untuk memastikan bahwa board NodeMCU bekerja dengan baik. Pengujian dilakukan dengan menghubungkan NodeMCU ke jaringan Wi-Fi atau Access Point yang menyediakan akses internet. Pada board NodeMCU sudah di setting sebelumnya untuk terkoneksi pada SSID yang sudah ditentukan. Hasil pengujiannya ditampilkan pada serial monitor yang ditampilkan pada gambar 6 .

Pada gambar 6 menunjukkan bahwa NodeMCU berhasil terhubung ke SSID yang bernama SyfeiKarim dan dapat terhubung ke internet. Setelah itu, NodeMCU juga berhasil terhubung ke web server thingboard dengan url iot.politanisamarinda.ac.id.

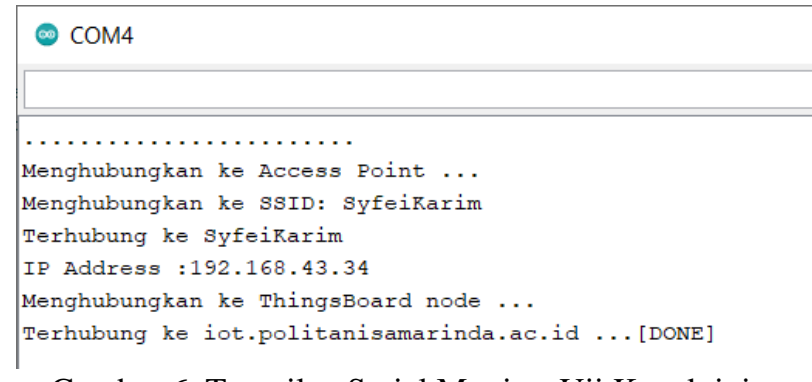

Gambar 6. Tampilan Serial Monitor Uji Konektivitas

\section{Pengujian Fungsionalitas Sistem}

Tujuan dari pengujian ini adalah untuk mendapatkan hasil yang optimal dari perancangan sistem monitoring pada tanaman hidroponik menggunakan protokol Message Queuing Telemetry Transport (MQTT) dengan melakukan pengujian secara menyeluruh pada sistem.

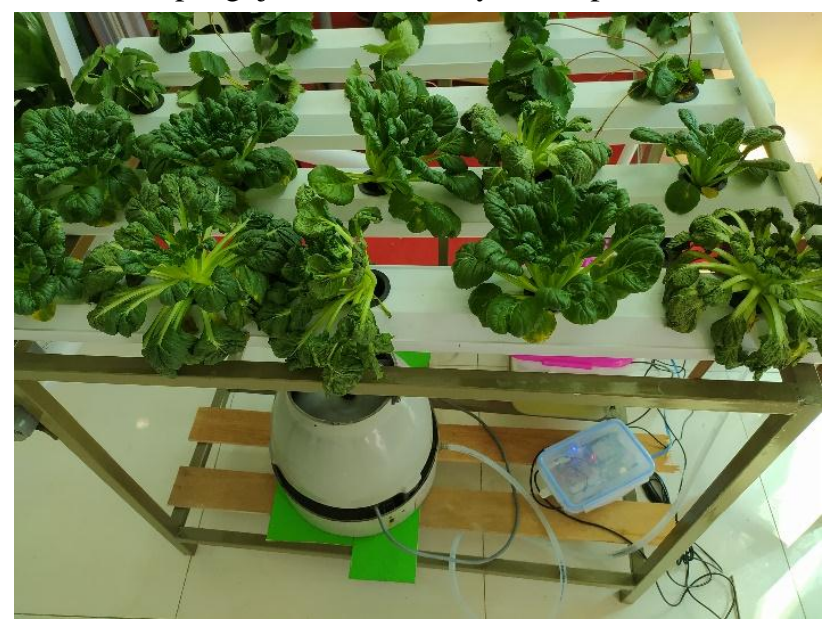

Gambar 7. Kondisi pada Tanaman Hidroponik

Pada gambar 6 menunjukkan kondisi sistem yang diletakkan pada tanaman hidroponik. Pada pengujian keseluruhan sistem, perangkat keras dari sistem ditempatkan berdekatan dengan alat humidifier dan juga air tanaman hidroponik untuk mendeteksi suhu, kelembaban, $\mathrm{pH}$, dan nutrisi air (ppm) yang datanya dikirim melalui jaringan $\mathrm{Wi}-\mathrm{Fi}$ menggunakan protokol MQTT ke server Thingsboard, terlihat bahwa ada perubahan data pada sensor yang tercatat dalam chart dan grafik seperti pada gambar 7 .

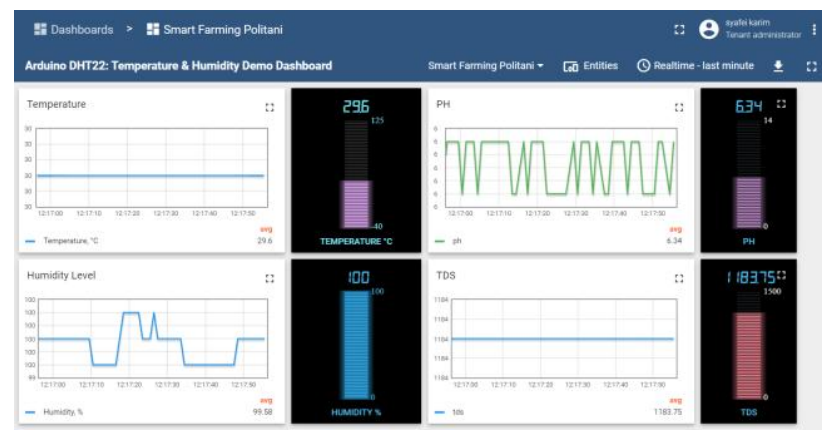

Gambar 8. Tampilan Data pada Thingsboard

Pada gambar merupakan tampilan layar ketika Thingsboard dapat menampilkan data yang dideteksi oleh 
sensor dengan baik. Perubahan data sensor yang terjadi dapat dilihat dalam bentuk grafik dan chart pada Thingsboard.

\section{CONCLUSION}

Dari hasil pembahasan yang dilakukan pada penelitian yang berjudul "Sistem Monitoring pada Tanaman Hidroponik menggunakan Arduino Uno dan NodeMCU" maka dapat diambil kesimpulan bahwa implementasi konsep IoT pada tanaman hidroponik menghasilkan sebuah perangkat yang dapat melakukan monitoring tanaman hidroponik dari jarak jauh dan juga membantu dalam pengecekan kondisi air tanaman.

Berdasarkan hasil pengujian, board NodeMCU dapat mengirimkan data ke server dengan lancar. Semua datadata sensor terkirim dengan baik ke server Thingsboard dengan menampilkan data dalam bentuk chart dan grafik.

\section{REFERENCES}

Association, G., 2014. Understanding the Internet of Things (IoT). London: GSMA Connected Living.

Buana, Z., O. C. \& E., 2019. Sistem Pemantauan Tanaman Sayur dengan Media Tanam Hidroponik menggunakan Arduino. Jurnal Teknik Elektro dan Vaksional, Februari, Volume Vol. V, pp. 74-80.

Ciptadi, P. W. \& Hardyanto, R. H., 2018. Penerapan Teknologi IoT pada Tanaman Hidroponik menggunakan Arduino dan Blynk Android. Jurnal Dinamika Informatika, September, Volume Volume 7, pp. 29-40.

Crisnapati, P. N., Wardana, I. N. K., Aryanto, I. K. A. A. \& Hermawan, A., 2018. Hommons: Hydroponic Management and Monitoring System for an IoT based NFT Farm using Web Technology. s.1., IEEE.

D. R., A. D. \& P. S., 1990. Hydroponic culture of crops in the Philippines: Problems and Prospect.. International Seminar on Hydroponic Culture of High Value Crops in the Tropics in Malaysia, 25-27 November.

E., Arief, S. N. \& Cordova, M. D., 2020. Implementasi IOT Pada Smartgreenhouse Berbasis Raspberry Pi menggunakan Aplikasi Android. s.l., s.n.

Pamungkas, G., Purwalaksana, A. Z., Djamal, M. \& Amina, N. S., 2017. Rancang Bangun Hidroponik Sistem Nutrient Film Technique Otomatis Berbasis Arduino. Prosiding SNIPS, 26-27 Juli.

Prasetyo, A., Nurhasan, U. \& Lazuardi, G., 2018. Implementasi IoT pada Sistem Monitoring dan Pengendali Sirkulasi Air Tanaman Hidroponik. Jurnal Informatika Polinema, November, Volume Volume 5, pp. 31-36.

Prayitno, W. A., A. M. \& D. S., 2017. Sistem Monitoring Suhu, Kelembaban, dan Pengendali Penyiraman Tanaman Hidroponik menggunakan Blynk Android. Jurnal Pengembangan Teknologi Informasi dan Ilmu Komputer, April, Volume Vol. 1, No. 4, pp. 292-297.
Putra, R. M., 2018. Budidaya Tanaman Hidroponik DFT pada Tiga Kondisi Nutrisi yang Berbeda, Bandar Lampung: Universitas Lampung.

Setiadi, D. \& Muhaemin, M. N. A., 2018. Penerapan Internet of Things (IoT) pada Sistem Monitoring Irigasi (Smart Irigasi). Jurnal Infotronik, Desember.Vol. 3(No. 2).

Setiawan, N. D., 2018. Otomasi Pencampur Nutrisi Hidroponik Sistem NTF (Nutrient Film Technique) Berbasis Arduino Mega 2560. Jurnal Teknik Informatika Unika St. Thomas (JTIUST), Desember.Vol. 3(No. 2).

Wilianto \& Kurniawan, A., 2018. Sejarah, Cara Kerja dan Pemanfaatan Internet of Things. Jurnal Matrix, Vol. 8(No. 2). 